\title{
Investigation of High-Strength Electroformed Ni for Microprobes*
}

\author{
Teppei KIMURA**, Naoki ARITA***, \\ Hajime FUKINBARA*** and Tadashi HATTORI**
}

\begin{abstract}
We have developed a microprobe that achieves low contact resistance under low contact force only for gold pads. However, in the case of $\mathrm{Al}$ pads, an oxide layer formed on the aluminum pad surface obstructs stable contacting, so higher contact force with a strong probe is required. The present study attempts to enhance the strength of the probe material by improving its mechanical properties. It is said that grain downsizing, functionally alloying, or impurity addition can increase material strength. Our study has adopted impurity addition to the electroforming bath because the process can be controlled. Thus, high-strength electroformed Ni has successfully been obtained. Improved Ni has a high Vickers hardness of Hv600 compared with Hv450 for conventional nickel, and a high Young's modulus of $E=200 \mathrm{GPa}$ compared with $E=150 \mathrm{GPa}$ for conventional nickel.
\end{abstract}

Key Words: Electroforming, Sodium Allylsulfonate, Grain Size

\section{Introduction}

The probe card is a tool used in testing each IC chip on a silicon wafer on which ICs have been formed. The probe card electrically connects each IC chip to the test system. To this end, it comprises a printed circuit board (PCB) to be connected with the test system, and probes to be connected with the external contact terminals (bonding pads) on IC chips, as shown in Fig. 1.

The probe card is expected to satisfy various requirements, such as low and stable contact resistance, highfrequency response, and fine-pitch probes. Of these, the

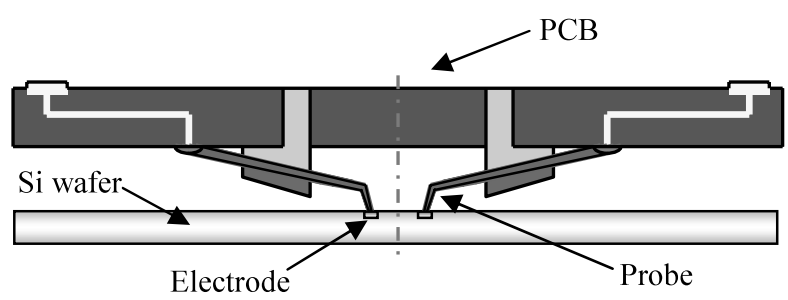

Fig. 1 Cross-section of probe card

* Received 9th August, 2005 (No. 05-4202)

** Laboratory of Advanced Science and Technology for Industry, University of Hyogo, 3-1-2 Kamigori-cho, Ako, Hyogo 678-1205, Japan. E-mail: t-kimura@lasti.u-hyogo.ac.jp

*** Japan Electronic Materials CORP, 2-5-13 Nishinagasucho, Amagasaki-City, Hyogo 660-0805, Japan need for finer-pitch probes is especially strong, due to the recent trend toward ever-smaller IC chips, and the resultant decrease in the size of the bonding-pad. With probes produced by conventional mechanical fabrication processing, however, the finest pitch achievable is $35 \mu \mathrm{m}$. Development of a new type of microprobe has been long awaited.

Against this background, we have been studying the applicability of LIGA micro machining technique ${ }^{(1)}$ to probe-card fabrication. In our past $\operatorname{study}^{(2)}$, we successfully fabricated three-dimensional nickel microprobes each extending from tip to beam all at once in one cycle of the LIGA X-ray lithography process. Testing with the experimentally fabricated microprobe has verified its low contact resistance for Au pads. For Al-Cu pads on which an oxide film exists, however, the probe is required to break the film to achieve a low and stable contact resistance, which means the need for contact-force improvement. The probe contact force can be improved by various methods, such as increasing the probe thickness, or increasing Young's modulus. If the probe thickness is excessively large, however, the tip can deviate to the side when the probe card is moved. Increasing the thickness is therefore impractical. We focused on an approach of increasing the Young's modulus of the probe material. In the LIGA process, microprobes are fabricated by electroforming. Among various methods available for increasing the strength of electroformed material, such as alloying 
and grain downsizing, the present paper studies bath additives that are considered to be effective in suppressing crystalline precipitation.

\section{3-Dimentional Microprobe}

The microprobe has been developed to respond to the recent trend toward smaller IC chips. It is fabricated by forming a probe mold using LIGA X-ray lithography and $\mathrm{Si}$ anisotropic etching ${ }^{(3)}$, and electroforming a nickel probe in the mold. Figure 2 shows the steps in the microprobe fabrication process. First, a Si substrate is anisotropically etched to create a slope that defines the probe-mold shape in the Z-axis direction. Next, a thick resist layer is formed over the substrate surface. Then, $\mathrm{X}$-ray lithography is performed to form the probe-mold shape in the $\mathrm{X}$ and $\mathrm{Y}$ directions. Since this process uses $\mathrm{X}$-rays, it is virtually free from the influence of diffraction, thus enabling accurate three-dimensional, which would be difficult with UV lithography. Figure 3 shows SEM photographs of microprobes experimentally fabricated by the abovementioned process. Each microprobe is $20 \mu \mathrm{m}$ wide and $50 \mu \mathrm{m}$ thick, with the tip portion being $180 \mu \mathrm{m}$ thick. Very fine three-dimensional probes, each having a tip and beam, can successfully be produced in one cycle of the LIGA X-ray lithography process. Using X-ray lithography makes it possible to fabricate microprobes whose beam is $50 \mu \mathrm{m}$ thick.

Despite the very small overall size, each probe allows tip deflection by $80 \mu \mathrm{m}$ while maintaining a contact force of $3 \mathrm{mN}$. With the aim of further improving the probe

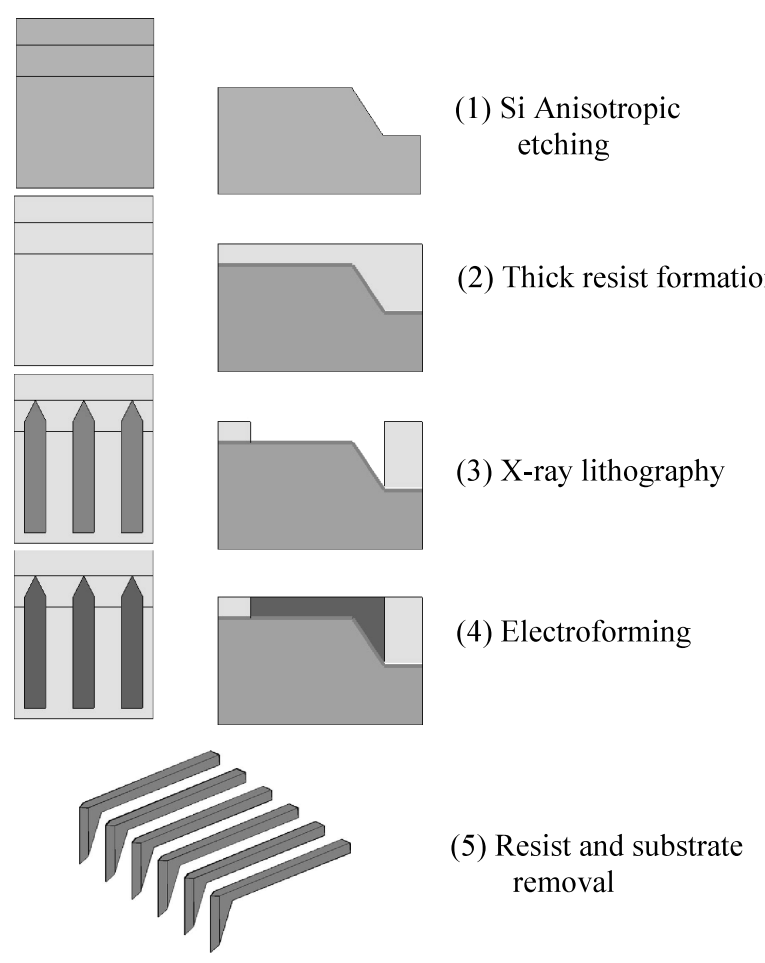

Fig. 2 Fabrication process of 3-dimensional microprobe contact force for Al pads, we studied how to enhance the strength of the probe material. We set a Vickers hardness of Hv600 and Young's modulus of $E=180 \mathrm{GPa}$ as the material's target mechanical property values to be achieved.

\section{Experimental Method}

\subsection{Preparation of electroforming bath}

Improving the microprobe contact force without changing its shape and size requires an increase in material strength. Since the microprobe is Ni-electroformed, research was conducted to increase the strength of the electroformed material. The strength of the electroformed material can be increased by alloying, grain downsizing, etc. Our study focused on allylsulfonate sodium, an additive considered to be effective in downsizing grains and controlling crystal orientation ${ }^{(4)}$. For comparison, research was also carried out with sodium saccharin, a commonly used additive. Tables 1 and 2 specify the bath compositions and electroforming conditions for sodium allylsulfonate and saccharin additives, respectively.

\subsection{Method for evaluating mechanical properties}

For the electroformed Ni layer produced using the abovementioned bath, we measured the hardness and Young's modulus, major mechanical properties important for microprobes. Although the hardness of the electro-

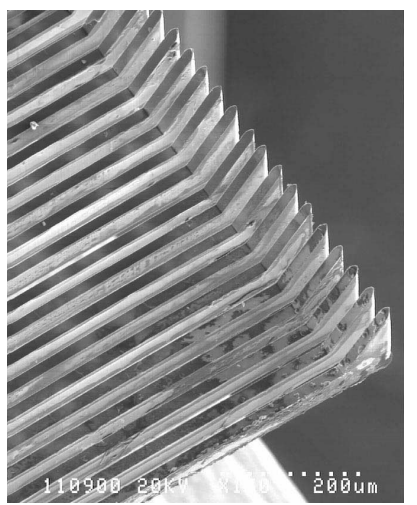

(a) Whole view

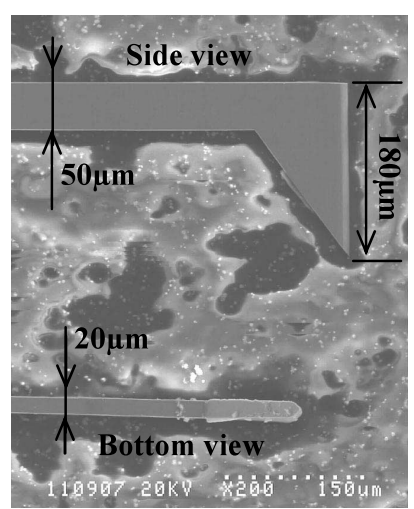

(b) Side and bottom views
Fig. 3 SEM photographs of microprobe

Table 1 Bath composition and electroforming condition (sodium allylsulfonate)

\begin{tabular}{l|c}
\hline \multicolumn{2}{c}{ Bath composition } \\
\hline Ni(II) sulfate hexahydrate $(\mathrm{g} / \mathrm{L})$ & 240 \\
\hline Ni(II) chloride hexahydrate $(\mathrm{g} / \mathrm{L})$ & 45 \\
\hline Boric acid $(\mathrm{g} / \mathrm{L})$ & 30 \\
\hline Sodium lauryl sulfate $(\mathrm{g} / \mathrm{L})$ & 0.04 \\
\hline \multicolumn{2}{c}{ Electroforming condition } \\
\hline \multicolumn{2}{c}{3} \\
\hline PH allylsulfonate $(\mathrm{g} / \mathrm{L})$ & 3.5 \\
\hline Bath temperature $(\mathrm{K})$ & 313 \\
\hline Current density $\left(\mathrm{A} / \mathrm{dm}^{2}\right)$ & 2 \\
\hline Anode plate & Nickel \\
\hline
\end{tabular}


Table 2 Bath composition and electroforming condition (saccharin)

\begin{tabular}{l|c}
\hline \multicolumn{2}{c}{ Bath composition } \\
\hline Ni(II) sulfate hexahydrate $(\mathrm{g} / \mathrm{L})$ & 240 \\
\hline Ni(II) chloride hexahydrate $(\mathrm{g} / \mathrm{L})$ & 45 \\
\hline Boric acid $(\mathrm{g} / \mathrm{L})$ & 30 \\
\hline Sodium lauryl sulfate $(\mathrm{g} / \mathrm{L})$ & 0.04 \\
\hline Saccharin $(\mathrm{g} / \mathrm{L})$ & 1 \\
\hline \multicolumn{2}{c}{ Electroforming condition } \\
\hline PH & 4.0 \\
\hline Bath temperature $(\mathrm{K})$ & 313 \\
\hline Current density $\left(\mathrm{A} / \mathrm{dm}^{2}\right)$ & 2 \\
\hline Anode plate & Nickel \\
\hline
\end{tabular}

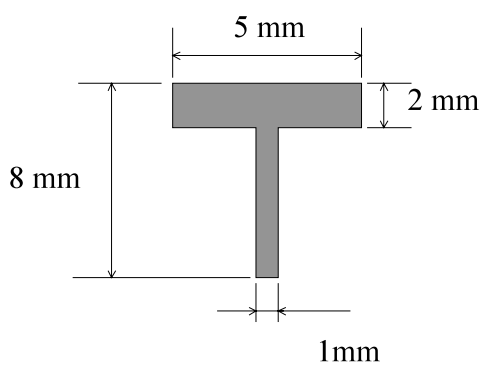

Fig. 4 Evaluation sample

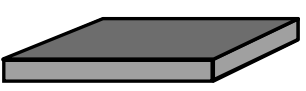

(a) Seed layer formation

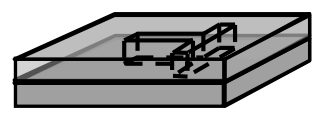

(c) UV lithography

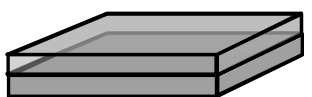

(b) Thick resist formation

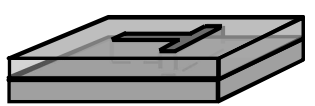

(d) Electroforming and lapping

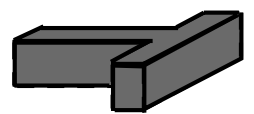

(e) Resist and substrate removal

Fig. 5 Fabrication process of evaluation sample

formed layer can be measured with the Vickers hardness test, no common measurement method has yet been established for Young's modulus. For simplified measurement of Young's modulus, a T-shaped evaluation sample shown in Fig. 4 was prepared using the UV lithography/electroforming process steps shown in Fig. 5. A bending test was conducted on this sample to identify the relationship between displacement and reaction force, based on which Young's modulus was obtained through the calculation. Figure 6 shows the construction of the bending test system used. The evaluation sample, secured on the $\mathrm{X}-\mathrm{Y}-\mathrm{Z}$ stage of the system, is pressed against the needle fixed to the precision electronic scale, and the load and displacement are then read on the scale.

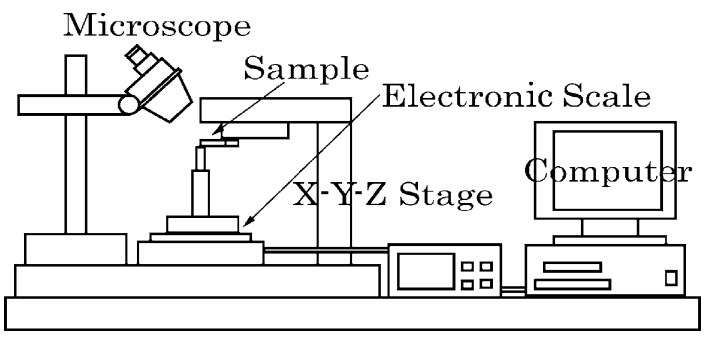

Fig. 6 Measurement system for Young's modulus

Table 3 Mechanical properties of experimental Ni

\begin{tabular}{|l|c|c|}
\hline & $\begin{array}{c}\text { Vickers } \\
\text { hardness }\end{array}$ & $\begin{array}{c}\text { Young's } \\
\text { modulus }\end{array}$ \\
\hline $\begin{array}{l}\mathrm{Ni} \\
\text { (Sodium allylsulfonate) }\end{array}$ & 610 & $\begin{array}{c}180-200 \\
\mathrm{GPa}\end{array}$ \\
\hline $\begin{array}{l}\mathrm{Ni} \\
\text { (Saccharin) }\end{array}$ & 435 & $\begin{array}{c}150-175 \\
\mathrm{GPa}\end{array}$ \\
\hline
\end{tabular}

\subsection{Method for evaluating crystal grain size and orientation}

For experimentally produced electroformed Ni material, we evaluated the influence of crystal grain size and orientation on the mechanical properties. In general, the grain size of electroformed $\mathrm{Ni}$ material enhanced in strength by adding an impurity to the bath is so small (several tens of nanometers) ${ }^{(4)}$ that it is difficult to measure under an ordinary microscope. We therefore used X-ray diffraction analysis, since it can measure the grain size and preferred orientation simultaneously. Electroformed $\mathrm{Ni}$ samples were prepared specially for the purposes of mechanical property evaluation. The Rigaku RINT-1500 $\mathrm{X}$-ray diffractometer was used as the analytical equipment. From the analysis results, the grain size was calculated using the Scherer equation ${ }^{(5)}$.

\section{Experimental Results and Discussion}

\subsection{Vickers hardness and Young's modulus}

The hardness of each evaluation sample was measured using a micro-Vickers hardness testing machine (HM-114, Akashi). Young's modulus was measured by the method described below, using the test system shown in Fig. 6. The evaluation sample was fixed at its wider end to a carbide jig and secured to the test system so that the sample was cantilevered. A displacement load was applied to this sample while the reaction force was measured. Young's modulus was calculated from the results obtained. To ensure an accurate calculation, the sample thickness and distance from the cantilever fixing point to the point of action, measured in advance, were taken into account in the calculation. Table 3 gives the Vickers hardness and Young's modulus of each sample. Those of the electroformed Ni sample produced with sodium allylsulfonate added to the bath are considerably higher than those of the sample produced with saccharin added to the bath, 
clearing the initially set target values.

\subsection{Heat resistance of electroformed $\mathrm{Ni}$}

In assembling microprobes into a probe card in a later stage, it will be necessary to solder the probes to an intermediate substrate and resin-bond the substrate to a PCB. These processes should involve heating the probes. We therefore evaluated the heat resistance of electroformed $\mathrm{Ni}$ material. Each sample prepared for mechanical properties evaluation was heat-treated (annealed) on a hot plate at various temperatures from $373 \mathrm{~K}$ to $573 \mathrm{~K}$ (ordinary joining temperature) in increments of $50 \mathrm{~K}$, and the Vickers hardness of each sample was measured at each temperature. The annealing duration was set at $1 \mathrm{~h}$, taking into account the bonding-resin cure time. Figure 7 shows the relationship between Vickers hardness and annealing temperature. The hardness of electroformed Ni produced with saccharin added to the bath continues to increase until the annealing temperature reaches $423 \mathrm{~K}$, but thereafter decreases sharply. In contrast, the hardness of electroformed Ni produced with sodium allylsulfonate added to the bath remains mostly constant until the temperature reaches $523 \mathrm{~K}$ and thereafter decreases rapidly. This result supports the superiority of sodium-allylsulfonate-using $\mathrm{Ni}$ to saccharin-using $\mathrm{Ni}$, in terms of heat resistance, promising freedom in subsequent assembly processing.

\subsection{Crystal grain size}

The abovementioned results verify the superiority of electroformed Ni produced with sodium allylsulfonate added to the bath, for all of the Vickers hardness, Young's modulus and heat resistance. Predicting that these superior properties might be due to the crystal grain size and orientation, we measured the crystal grain size and orientation using X-ray diffraction. For comparison purposes, this measurement was also carried out for electroformed Ni produced using an additive-free bath. Figure 8 shows the X-ray diffraction patterns of respective electroformed $\mathrm{Ni}$ samples. While the electroformed Ni produced using the additive-free bath has (220) preferred orientation,

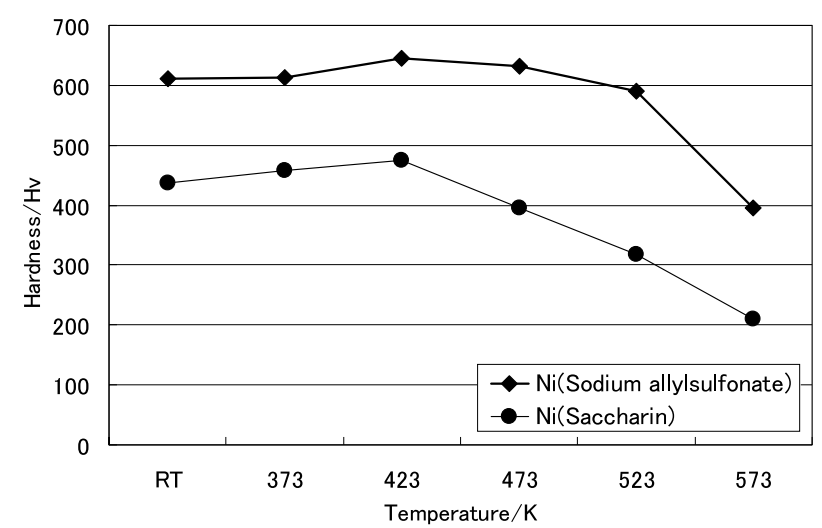

Fig. 7 Relationship between Vickers hardness and annealing temperature those produced with saccharin and sodium allylsulfonate added to the bath have (200) and (111) preferred orientations, respectively.

From these X-ray diffraction patterns, grain size was calculated using the following Scherer equation:

$$
t=0.9 \lambda /(B \cos \theta)
$$

where $t$ is the grain size (nm), $\lambda$ the wavelength (nm), $B$ the half bandwidth (rad), and $\theta$ the diffraction angle.

Table 4 shows the calculated results. The grain sizes of electroformed $\mathrm{Ni}$ samples produced using additivecontaining baths are smaller than that produced using the additive-free bath, indicating the higher hardness of the former. However, no significant difference was observed in grain size between saccharin-using $\mathrm{Ni}$ and sodium-

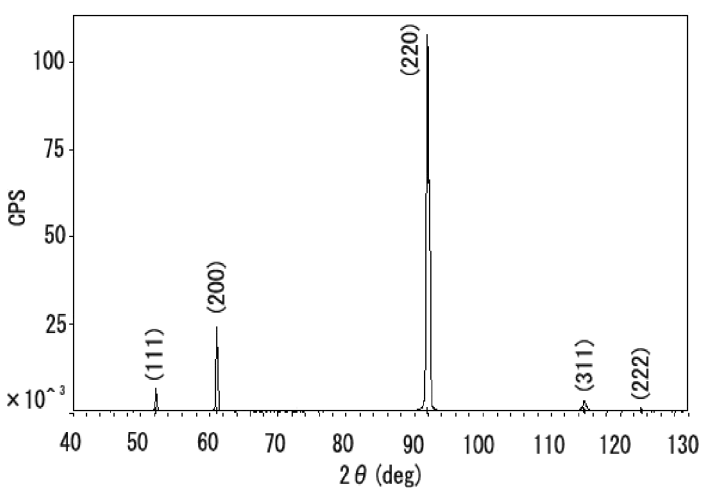

(a) $\mathrm{Ni}$ (Additive free)

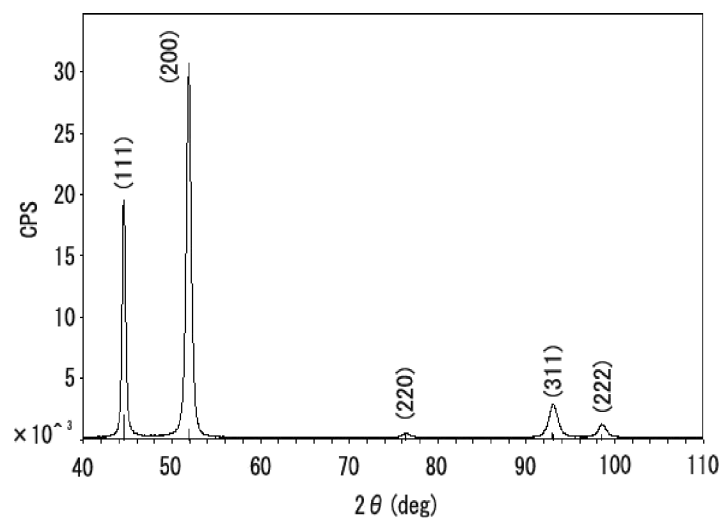

(b) $\mathrm{Ni}$ (Saccharin)

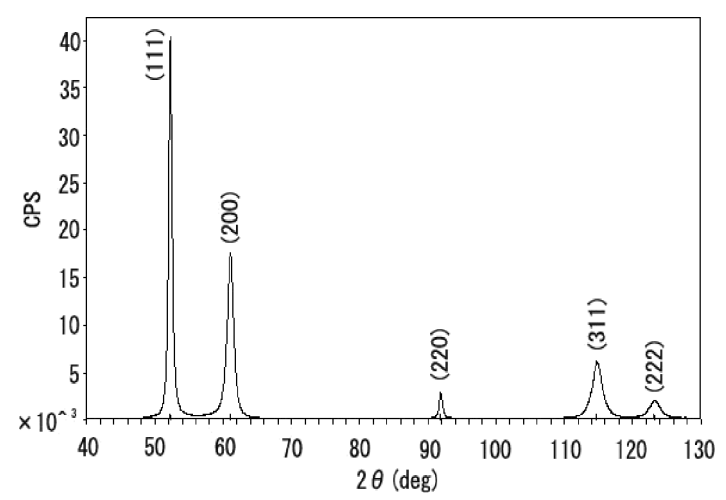

(c) $\mathrm{Ni}$ (Sodium allylsulfonate)

Fig. 8 X-ray diffraction patterns of electroformed Ni 
Table 4 Grain size of various kinds of electroforming $\mathrm{Ni}$

\begin{tabular}{|c|c|}
\hline Additive & Grain Size $(\mathrm{nm})$ \\
\hline Additive free & 40 \\
\hline Saccharin & 15 \\
\hline Sodium allylsulfonate & 18 \\
\hline
\end{tabular}

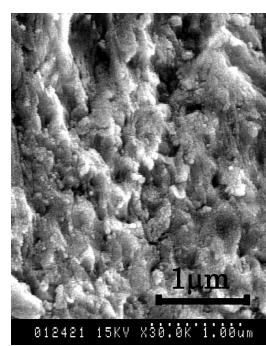

(a) RT

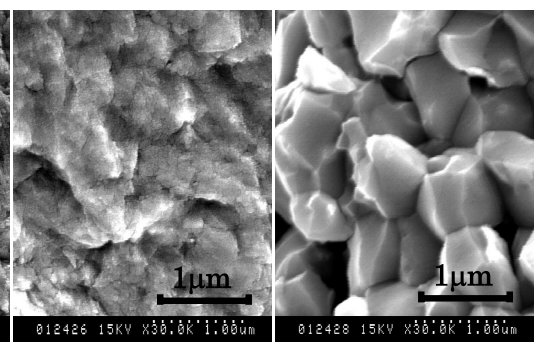

(c) $573 \mathrm{~K}$
$\mathrm{Ni}$ (Saccharin)

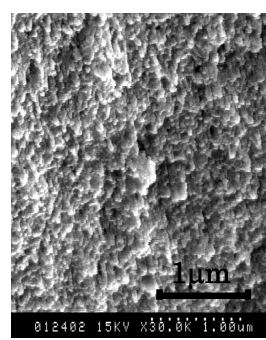

(a) RT

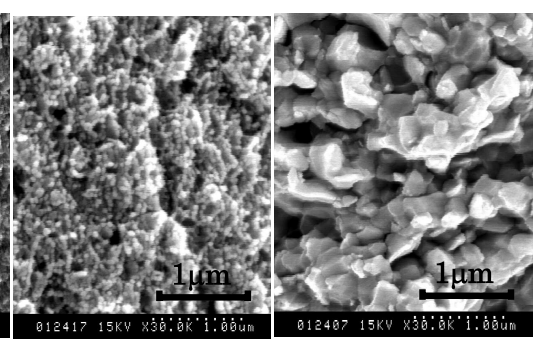

(b) $473 \mathrm{~K}$

(c) $573 \mathrm{~K}$

$\mathrm{Ni}$ (Sodium allylsulfonate)

Fig. 9 SEM photographs of fractured surface

allylsulfonate-using $\mathrm{Ni}$, despite a far higher Vickers hardness of the latter, as shown in Table 3. This cannot be explained by the Hall-Petch rule, which states that material hardness increases with a decrease in crystal grain size, since dislocations caused by plastic deformation more readily come in contact with boundaries, thus making it harder for grains to move ${ }^{(6)}$. Presumably, some unknown additive factor is working so that sodiumallylsulfonate-using Ni provides less dislocating motion than does saccharin-using $\mathrm{Ni}$, resulting in higher hardness despite the same grain size. In addition, the Vickers hardness of sodium-allylsulfonate-using $\mathrm{Ni}$ begins to decrease at an annealing temperature of $573 \mathrm{~K}$, while that of saccharin-using Ni begins to decrease at $473 \mathrm{~K}$, as shown in Fig. 7. This implies the higher effectiveness of sodium allylsulfonate than saccharin in suppressing grain growth.

To observe the grain growth status due to annealing temperature, each $\mathrm{Ni}$ sample annealed at $1 \mathrm{~h}$ was split by bending, and analyzed the fractured surface using scanning electron microscopy (SEM). Figure 9 shows the results.

The SEM analysis revealed the following: (1) when the annealing temperature is $473 \mathrm{~K}$, crystal grain growth can be observed in the electroformed Ni produced with saccharin added to the bath, but not in the electroformed $\mathrm{Ni}$ produced with sodium allylsulfonate added $(\mathrm{b}, \mathrm{e})$;

(2) when the annealing temperature is $573 \mathrm{~K}$, crystal grains are obviously coarser in the saccharin-using $\mathrm{Ni}$ than in sodium-allylsulfonate-using $\mathrm{Ni} \mathrm{(c,} \mathrm{f).} \mathrm{These} \mathrm{re-}$ sults confirm that sodium allylsulfonate added to the electroforming bath is effective in suppressing crystal grain growth during the annealing process.

From the X-ray diffraction patterns shown in Fig. 8, it is possible to identify the preferred orientation, but not the definite advantage of sodium-allylsulfonate-using $\mathrm{Ni}$ in terms of mechanical properties.

\section{Conclusions}

The microprobes of a probe card used in testing semiconductor IC chips are fabricated by lithography and $\mathrm{Ni}-$ electroforming. To improve the microprobe contact force, we attempted to increase the strength of electroformed $\mathrm{Ni}$ by adding an impurity to the bath. Evaluation of experimentally produced electroformed $\mathrm{Ni}$ revealed the following:

( 1 ) The electroformed Ni produced with sodium allylsulfonate added to the bath has a Vickers hardness of 610 and Young's modulus of 180 to $200 \mathrm{GPa}$, providing superior mechanical properties compared with those of the electroformed Ni produced with sodium saccharin added to the bath.

(2) A heat resistance test conducted on electroformed $\mathrm{Ni}$ samples revealed that whereas the Vickers hardness of saccharin-using $\mathrm{Ni}$ begins to decrease at an annealing temperature of $473 \mathrm{~K}$, that of sodiumallylsulfonate-using Ni remains virtually constant until the annealing temperature reaches $523 \mathrm{~K}$.

( 3 ) X-ray diffraction analysis for crystal orientation and grain size revealed that sodium-allylsulfonate-using $\mathrm{Ni}$ has the (111) preferred orientation. The grain size is mostly the same in the saccharin-using $\mathrm{Ni}$ material and sodium-allylsulfonate-using $\mathrm{Ni}$ material, ranging between 15 and $18 \mathrm{~nm}$.

( 4 ) The fractured surface of each of these electroformed $\mathrm{Ni}$ samples, observed after annealing under the same conditions, shows that sodium allylsulfonate is effective in suppressing crystal grain growth.

In the future, we will apply this high-strength electroformed $\mathrm{Ni}$ to microprobes to verify its practical usability.

\section{References}

( 1 ) Becker, E.W., Ehrfeld, W., Hagmann, P., Maner, A. and Munchmeyer, D., Fabrication of Microstructures with High Aspect Ratios and Great Structural Heights by Synchrotron Radiation Lithography, Galvanoforming, and Plastic Molding, Microelectron. Eng., Vol.4 (1986), pp.35-42.

( 2 ) Kimura, T. and Hattori, T., Micro Probe Processing Using X-Ray Lithography 3-D Structural Micro Probe Report 1-, Proc. of 10th Symposium on Microjoining and Assembly Technology in Electronics (MATE), 
Japan, (2004), pp.433-436.

( 3 ) Tabata, O., Silicon Anisotropic Etching Using TMAH Solution, Journal of Surface Finishing Society of Japan, Vol.51, No.8 (2000), pp.767-770.

( 4 ) Kishimoto, K., Yoshioka, S., Kobayashi, K. and Sato, Y., Effects of Various Additives on the Characteristics of Electroplated Nickel Thin Films, Journal of Sur- face Finishing Society of Japan, Vol.54, No.10 (2003), pp.710-713.

( 5 ) Cullity, B.D., Elements of X-Ray Diffraction, Second Edition, (1980), Agune Gijutsu Center Co.

(6) Watanabe, T., Nano Plating, (2004), Nikkan Kogyo Shimbun Ltd. 